\title{
Note on the Disintegration of Wool in Abrasion Tests
}

\author{
By Herbert F. Schiefer and John F. Krasny
}

\begin{abstract}
The coating that formed on the abradant when a specimen of wool fabric was abraded and caused the rate of abrasion to increase approximately ten times in three successive tests was examined critically. Microchemical analyses showed that it had the same composition as the unabraded fabric. Infrared absorption curves of the coating and of the powder of the unabraded fabric, ground in a vibratory ball mill, showed the same absorption characteristics. Electron micrographs of the coating showed that it contained extremely small particles, many of which were approximately spherical in shape and about 100 to 200 Angstroms in size. Similar particles were observed in the abraded debris when the specimen was kept wet with water during the abrasion test and also in the powder into which the unabraded fabric was ground in the vibratory ball mill. It was concluded that the coating that formed on the abradant consisted of extremely small particles of wool, which appear to correspond in shape and size to the elemental structural units (keratin molecules) proposed in recent concepts of the structure of wool.
\end{abstract}

\section{Introduction}

Recent results obtained with the Schiefer abrasion testing machine on a wool fabric showed that the rate of abrasion increased approximately ten times when three specimens were tested successively with the same abradant. ${ }^{2}$ This effect was obtained with the spring steel blade abradant and also with the Pyrex rod abradant. It was found that this tremendous increase in the abrasive action of these two abradants ${ }^{3}$ was caused by a coating that formed on the surface of the abradant. The formation of a coating on the abradant surface has since been observed when a number of other wool fabrics were abraded, and the effect of the coating was always an increase in the rate of abrasion. Tests were made in which the air in the immediate vicinity of the abraded area of the wool specimen and the abradant surface was ionized by an alpha emitter, and it

\footnotetext{
1 The essential results of this paper were presented and discussed by Schiefer at the meeting of Committee D-13 on Textiles of the American Society for Testing Materials, March 16, 1949, New York, N. Y., and at the meeting of The Fiber Society, April 15, 1949, Clemson, S. C. This paper also appears in the December 1949 issue of the Textile Research Journal.

2 Herbert F. Schiefer, Lawrence E. Crean, and John F. Krasny, Improved single-unit Schiefer abrasion testing machine, J. Research NBS 42, 481 to 497 (1949) RP1988; Textile Research J. 19, 259 to 269 (May 1949); AST M Bulletin No. 159,73 to 78 , (July 1949).

3 This abradant was found to remain very constant in its abrasive action when many other types of textiles were tested. For other abradants, sucb as sandpaper, emerypaper, and cloth, the rate of abrasion decreased greatly in testing several successive specimens with the same abradant.
}

was found that the coating formed as readily on the abradant as without ionization of the air. The coating did not appear to form when the wool specimen was kept wet with water during the abrasion test.

In view of the great effect of the coating on the rate of abrasion and the important bearing that this observed effect has on the interpretation of the results of abrasion tests, it seemed essential to examine the nature of the coating very carefully. The results of this study are presented and discussed in this paper.

\section{Coating}

The coating that forms on the abradant, when a specimen of a wool fabric is abraded, is brittle, appears to form in ridges, and adheres tenaciously to the abradant surface. A typical example of the coating is shown in figure 1 , where the surface of one Pyrex rod of the abradant is completely coated; whereas the other rod, which was located at the outside periphery of the abradant and did not come in contact with the test specimen, is not coated. The diameter of these rods was $1 / 8$ in. In this test a 2-in.-diameter specimen was abraded so that the periphery of the abraded area always passes through the center of the Pyrex rod located at the center of the abradant. This central rod 


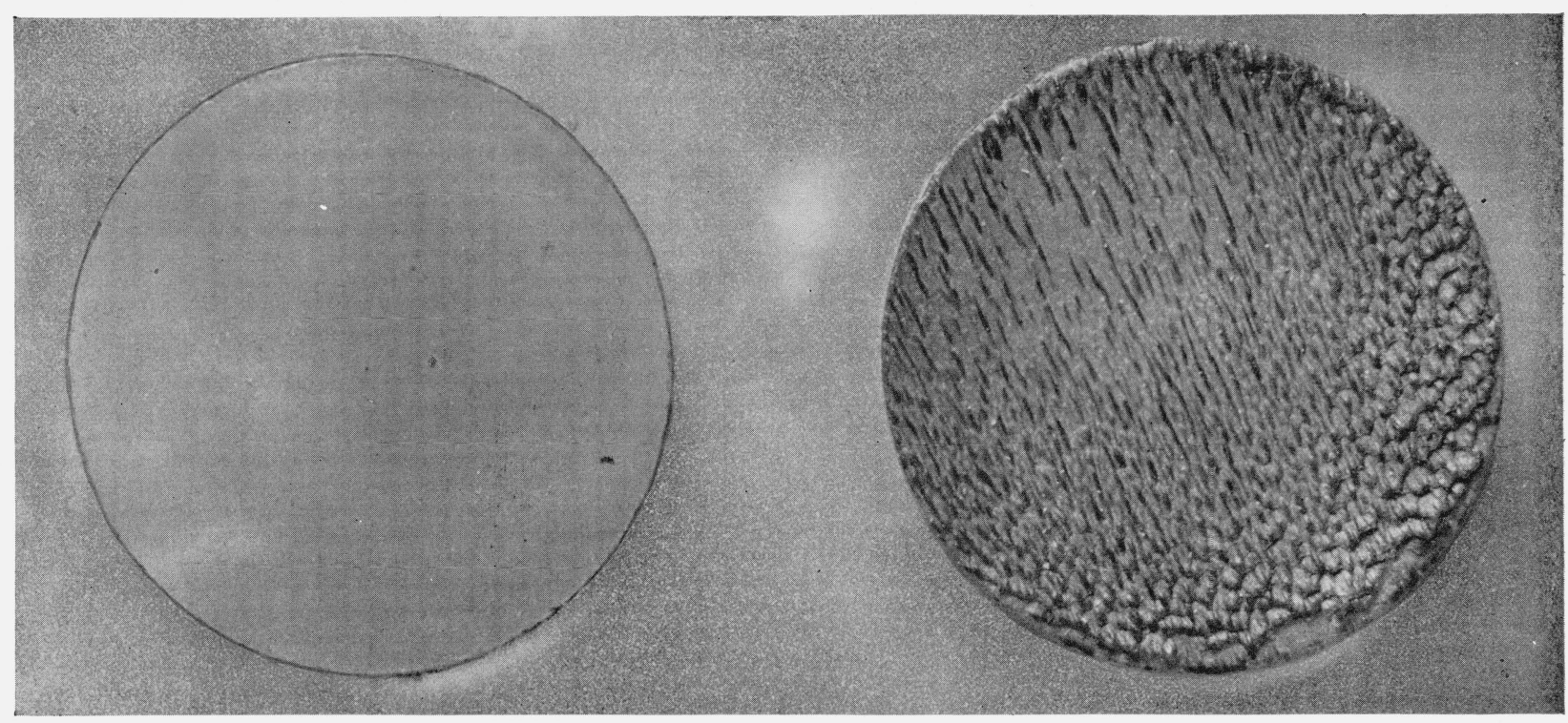

Figure 1. Uncoated and coated Pyrex rod of abradant.

Approximate magnification, $\times 22$.

and a group of rods located in concentric circles about it are shown in figure 2 . It is interesting to note that the coating on the central rod appears to build up in radial ridges, whereas the coating on the other rods appears to build up in more or less parallel ridges on each rod. These parallel ridges on the var-

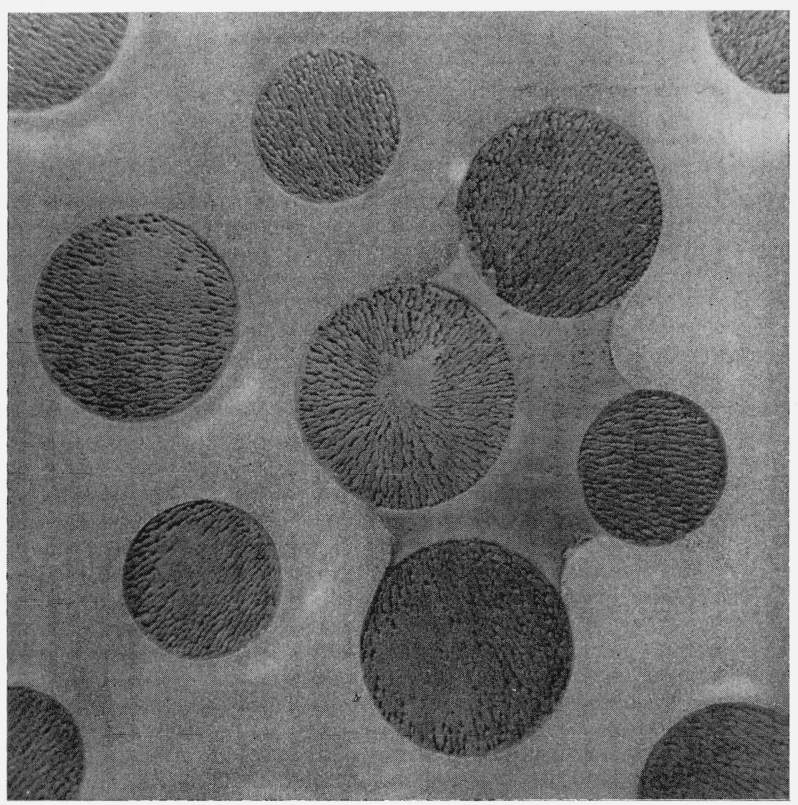

Figure 2. Coated Pyrex rods of abradant showing the ridges of the coating converging to the center of rotation of the abradant.

Approximate magnification, $\times 7$. ious rods, however, are all radial with respect to the central rod about which the abradant rotates.

In the mathematical solution for obtaining uniform abrasion, ${ }^{4}$ on which the Schiefer abrasion machine is based, it was pointed out that the direction of the instantaneous relative velocity between any point of the abraded area of the specimen and the abradant is always at right angles to the line that passes through the centers of rotation of the specimen and of the abradant. All the radii of the central Pyrex rod of the abradant coincide with this line once in each rotation. It follows, therefore, that the ridges of the coating on the rods are at right angles to the instantaneous relative velocity between the specimen and the abradant at the instant when each ridge coincides with the line joining the two centers of rotation. This close association between the alinement of the ridges and the direction of the instantaneous relative velocity, when each rod coincides with the line joining the two centers of rotation, suggests that the ridges are probably formed at these instants.

A higher magnification of a small portion of a coated rod is shown in figure 3 . The coating consists of extremely small particles that could not be resolved in the light microscope. It gave a positive test for protein with Millon's reagent.

\footnotetext{
${ }^{4}$ Herbert F. Schiefer,"Solution of problem of producing uniform abrasion and its application to the testing of textiles, J. Research NBS, 39, 1 to 10 (1947)_RP1807; Textile_Research J. 17, 360 to 368 (July 1947).
} 


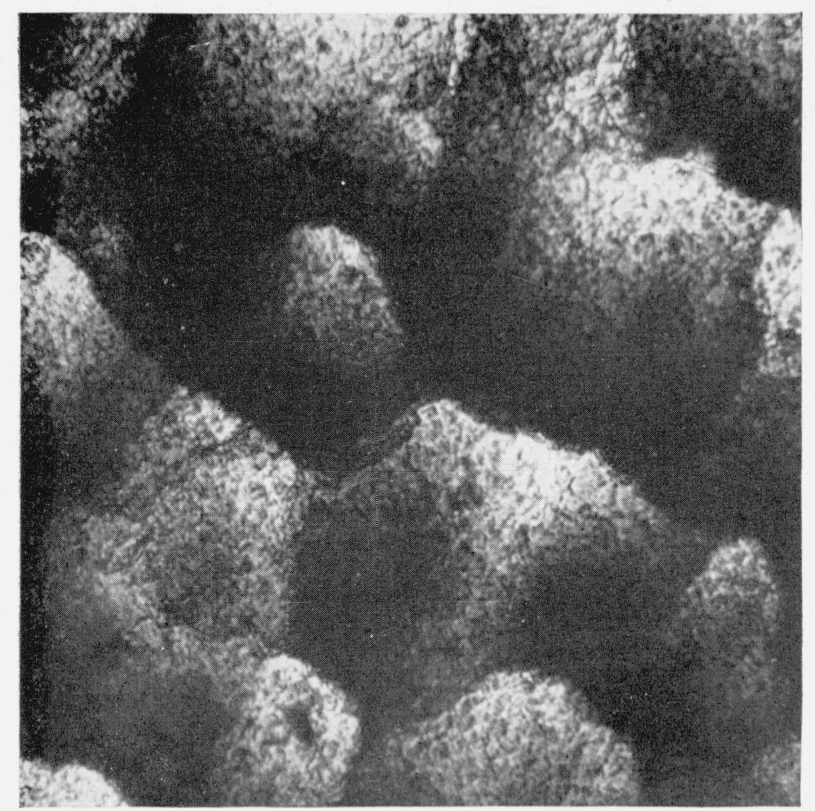

Figure 3. Magnified appearance of the coating on a Pyrex rod.

Approximate magnification. $\times 350$.

If the coating on a rod was moistened with water, it could be very readily lifted from the rod with a sharp razor blade. The layer of coating so removed seemed brittle after it became dry. It dispersed quite readily when it was placed in water and formed a cloudy suspension. It was not difficult to remove and collect a sufficient amount of the coating from the ends of the Pyrex rods for microchemical analyses, electron micrographs, and infrared absorption spectra.

\section{Microchemical Analysis}

The coating, which formed on the abradant when specimens of three different wool fabrics were abraded, was removed from the ends of the Pyrex rods as described in the preceding section.
A microchemical analysis was made of the coating of each fabric and also of a portion of each unabraded fabric. The results are given in table 1 . They show that the hydrogen, carbon, and sulfur composition of the coating is in each instance the same within experimental error, as of the unabraded fabric. The nitrogen content of the coating seems to be consistently and significantly lower than that of the fabric. The compositions of the three coatings and of the three fabrics are very nearly alike and are close to the values reported for wool in the American Wool Handbook. It is concluded that the coating, which formed on the abradant of these tests, is composed of extremely small particles of wool abraded off the wool fibers rather than a resinous or other finishing substance that was added to the wool fibers in manufacture. The supplier of one of the dyed wool fabrics stated that it contained no resinous finish. No reply was received from the supplier of the other dyed wool fabric.

\section{Electron Micrographs}

A small amount of the coating, removed from the abradant, was dispersed in water and a minute quantity of the dispersion was placed on a collodion film that was shadowed with chromium to enhance the contrast of the electron microscope image. Electron micrographs of the wool particles comprising the coating on the abradant for the undyed and blue dyed wool fabrics are shown in figures 4 and 5 . It can be clearly seen that the coatings consisted of many small particles that were approximately spherical in shape. Particles $200 \mathrm{~A}$ in size are definitely resolved, and some particles grade down to the particle size of the background, which is of the order of $100 \mathrm{~A}$. Many of the larger particles may be undispersed aggregates of the smaller particles. Others appear

TABLE 1. Microchemical analyses of three wool fabrics and of their coatings formed on the abradant

\begin{tabular}{|c|c|c|c|c|c|c|c|}
\hline Description & Hydrogen & Carbon & Nitrogen & Sulfur & Chlorine & Ash & $\begin{array}{c}\text { Oxygen } \\
\text { (obtained by } \\
\text { difference) }\end{array}$ \\
\hline Undyed wool, fabric... & $\begin{array}{l}\text { Percent } \\
6.7\end{array}$ & $\begin{array}{c}\text { Percent } \\
46.1\end{array}$ & $\begin{array}{c}\text { Percent } \\
\quad 15.0\end{array}$ & $\begin{array}{c}\text { Percent } \\
3.0\end{array}$ & Percent & Percent & $\begin{array}{l}\text { Fercent } \\
29.2\end{array}$ \\
\hline Undyed wool, coating & 7.0 & 45.6 & 14.5 & 3.2 & & & 29.7 \\
\hline Blue dyed wool, fabric & 6.7 & 46.1 & 14.3 & 4. 4 & None & 1.7 & 26.8 \\
\hline Blue dyed wool, coating. & 7.1 & 46.0 & 13.6 & 4.2 & None & 2.4 & 26.6 \\
\hline Tan dyed wool, fabric. & 6.8 & 46.3 & 15. 2 & 2.8 & 0.1 & . & 28.8 \\
\hline Tan dyed wool, coating & 6.8 & 45.4 & 14.5 & 3.3 & .1 & & 29.9 \\
\hline
\end{tabular}


to be larger sized particles that were abraded off the wool fibers during the abrasion test. ${ }^{5}$

It was mentioned earlier that the coating did not appear to form on the abradant when the specimen was kept wet with water during the abrasion test. Droplets of water, which were thrown off during the wet abrasion test made with the spring steel blade abradant, contained very finely dispersed abraded debris. A quantity of droplets was collected that yielded sufficient abraded material for electron micrographs and for infrared absorption spectra. Electron micrographs of the abraded wool particles, which were obtained during wet abrasion, are shown in figures 6 and 7 for the undyed and blue dyed wool fabrics. A large number of very small particles, approximately 100 to $200 \mathrm{~A}$ in size, can be observed as being produced during the wet abrasion test of these fabrics.

For infrared absorption spectra studies of cellulose, Rowen, Forziati, and Stone ground the cellulose to a very fine powder in a vibratory ball mill. The three wool fabrics were ground in the same manner. Electron micrographs of this finely ground powder are shown in figures 8 and 9 for the blue dyed wool fabric. Although most of the particles are very much larger than $200 \mathrm{~A}$, there are some particles of the order of 100 to $200 \mathrm{~A}$.

\section{Infrared Absorption Spectra}

Infrared absorption spectra were obtained for the coating that formed on the abradant, for the debris contained in the droplets of water that were thrown off during the wet abrasion test, and for the finely ground powder that was obtained when a small amount of the unabraded fabrics was ground in the vibratory ball mill. The infrared absorption spectra obtained for all of these three conditions for each of the three wool fabrics showed essentially the same absorption characteristics. The detailed discussion and interpretation of the infrared absorption spectra of wool is beyond the scope of this paper.

\footnotetext{
${ }^{5}$ In all abrasion tests of wool fabrics fragments of the wool fibers, scales, and corticle cells constitute part of the abraded debris. These fragments are not considered in this paper.
}

\section{Discussion}

The results presented in the preceding sections indicate that wool disintegrates into very small particles during both wet and dry abrasion tests with the Schiefer abrasion testing machine. Some of these small particles are roughly globular in shape and of the order of 100 to $200 \mathrm{~A}$ in size. They appear to correspond to the elemental particles (keratin molecules) recently suggested for the structural units of the protofibrils and matrix of wool. ${ }^{6} \quad$ They are also of about the same size as the thickness of the epicuticle or skin on the wool surface, ${ }^{7}$ which probably is the same as the smooth outer layer of the wool scales, which was shown to be worn off in abrasion tests with the Schiefer abrasion machine. ${ }^{8}$ During a recent visit to this Bureau, J. R. H. van Nouhuys, Vezelinstituut, T. N. O., Delft, Holland, stated to one of the authors that the Fibre Research Institute had examined the abraded debris under buttons of wool garments and found that in actual wear wool disintegrates into a very fine powder of approximately the same size as the particles that are worn off during the abrasion tests discussed in this paper.

Although complete answers have not been obtained as to why the abradant becomes coated during an abrasion test of a wool fabric, why the abrasive actions of the abradant is thereby greatly increased, and how the formation of the coating may be prevented, interesting information was obtained concerning the mechancial disintegration of wool. The very small disintegration products obtained appear to conform in size and shape to the elemental structural units proposed in recent concepts of the structure of wool. It is possible that the results of mechanical disintegration of wool in this type of an abrasion test can provide an additional tool in appraising the effects of chemical modifications and treatments of wool.

${ }^{6}$ J. L. Farrant, A. L. G. Rees, and E. H. Mercer, Structure of fibrous keratin, Nature 159, 535 to 536 (1947).

7 J. Lindberg, B. Philip, and N. Gralen, Occurrence of thin membrane in the structure of wool, Nature 162, 458 to 459 (1948); J. Lindberg, Allwörden's reaction, Textile Research J. 19, 43 to 45 (1949).

8 Max Swerdlow and Gloria S. Seaman, A Method for the electron microscopy of wool, J. Research NBS 41, 231 to 245 (1948) RP1921; Textile Research J. 18, 536 to 550 (1948). 


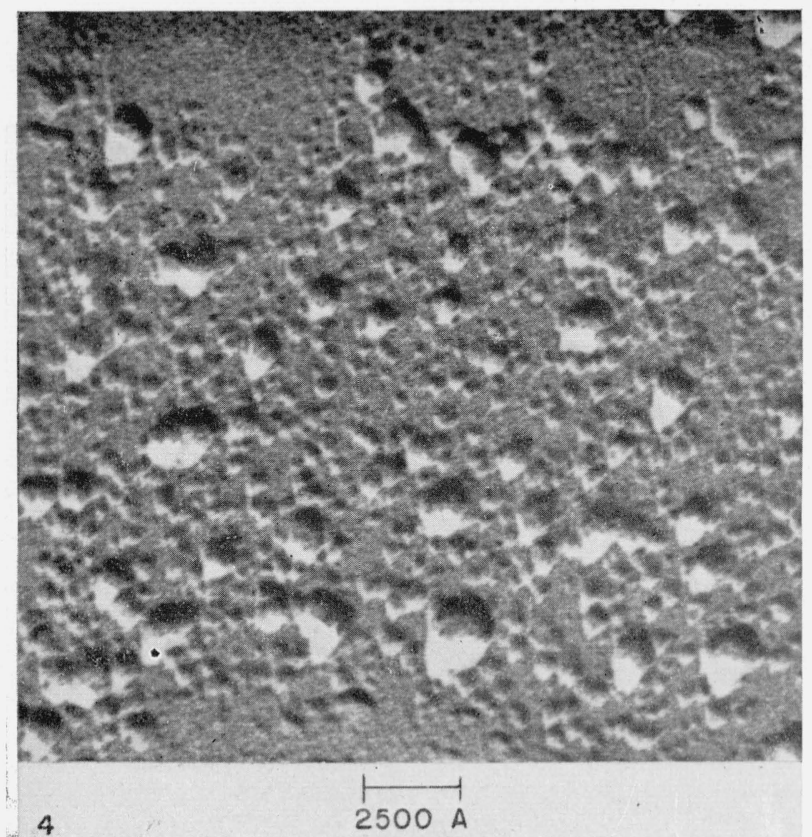

Figure 4. Chromium shadowed electron micrograph of the coating obtained from an undyed wool fabric (shadows are white).

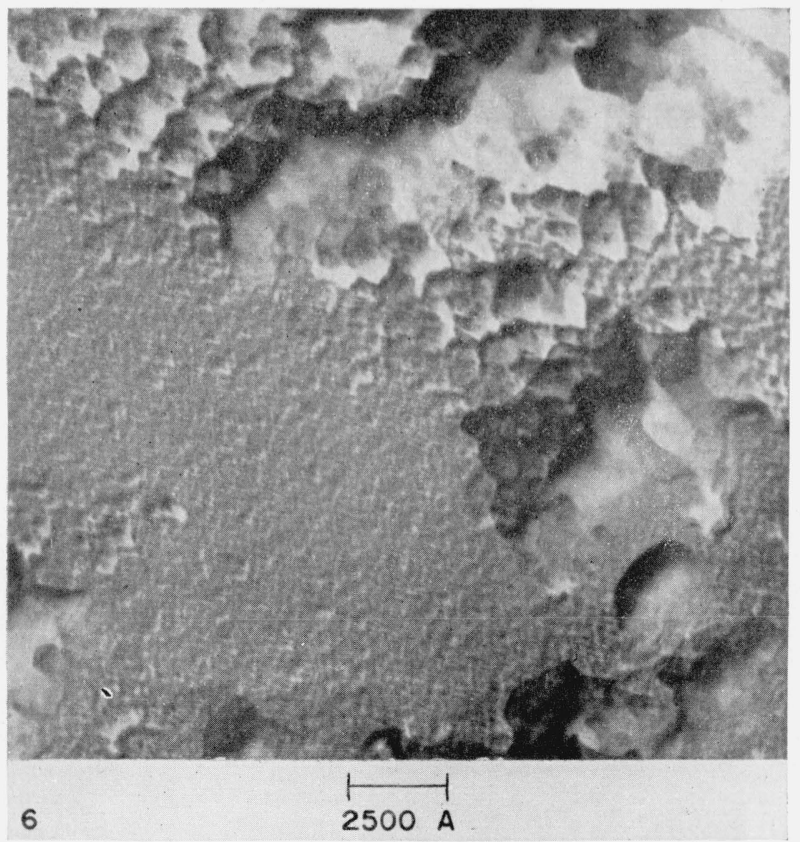

FiguRE 6. Chromium shadowed electron micrograph of the wet abraded debris from undyed wool fabric (shadows are white).

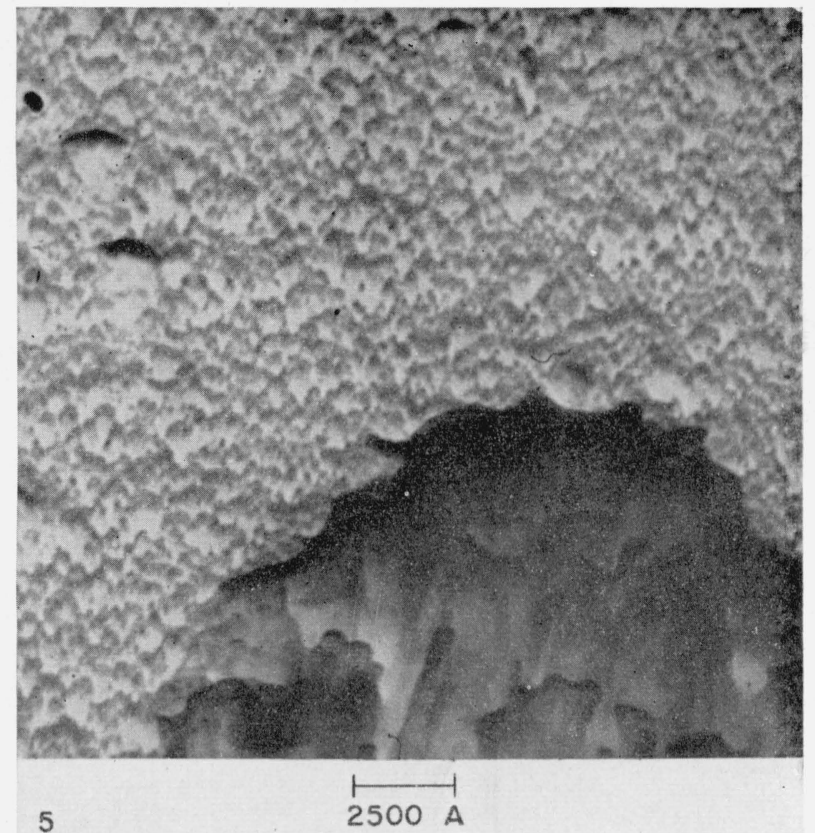

Figure 5. Chromium shadowed electron micrograph of the coating obtained from a blue dyed wool fabric (shadows are white).

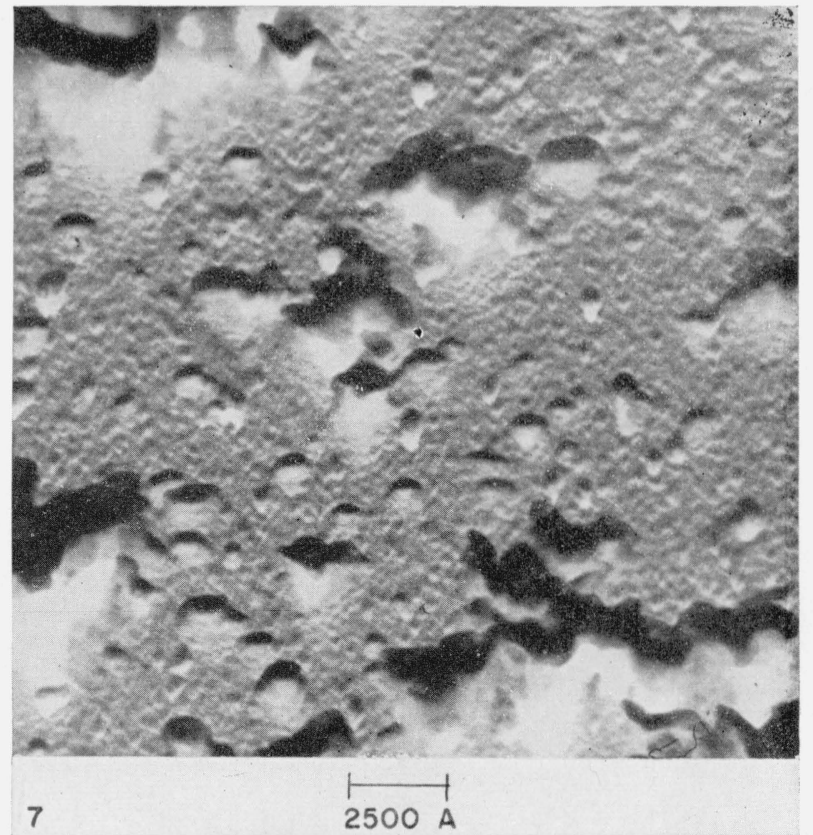

FIGURE 7. Chromium shadowed electron micrograph of the wet abraded debris from blue dyed wool fabric (shadows are white). 


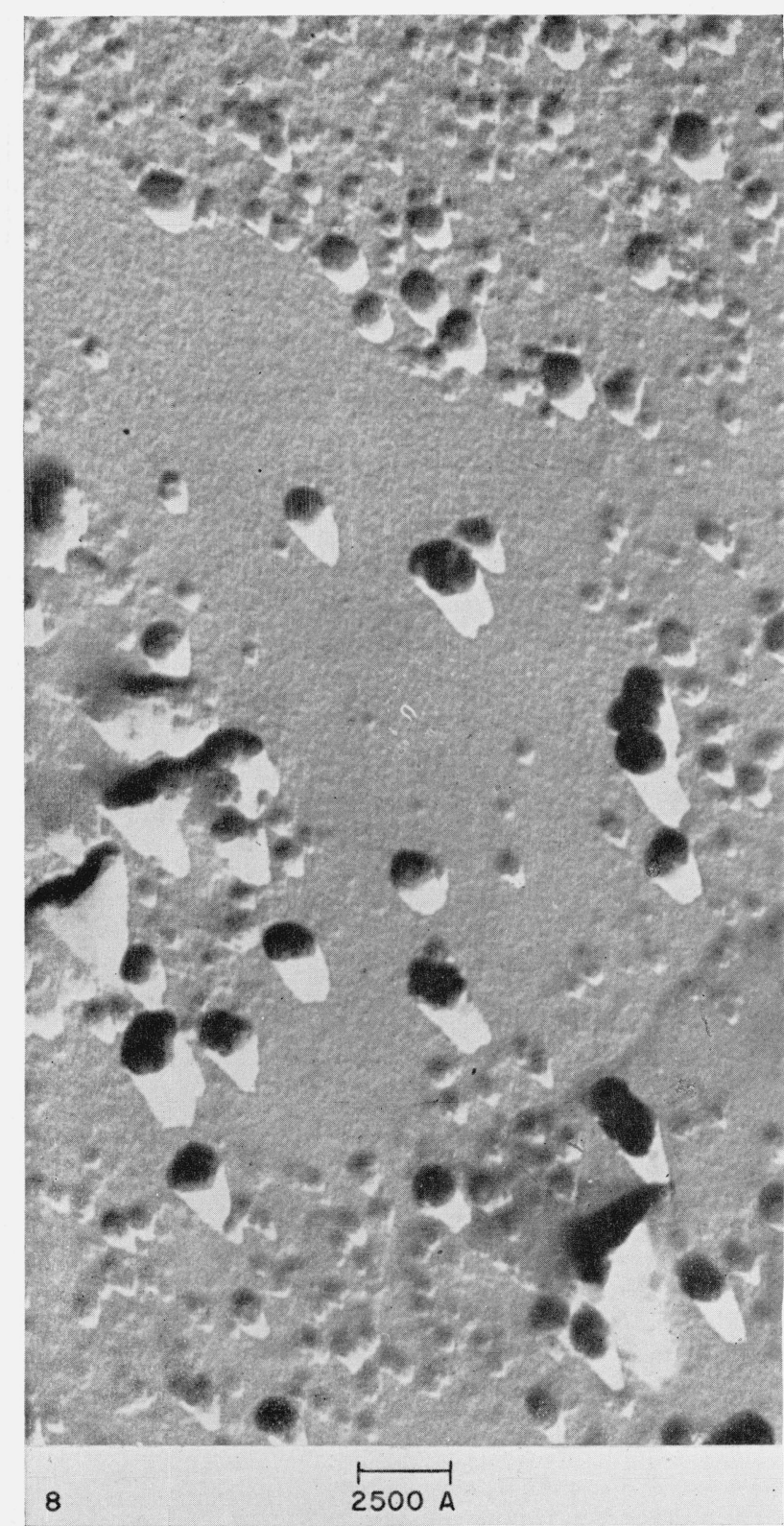

Figure 8. Chromium shadowed electron micrograph of ground powder of blue dyed wool fabric (shadows are white).

The authors are indebted to Rolf Paulson, who made the microchemical analyses; to Sanford Newman and Max Swerdlow, who made the electron micrographs; and to John Rowen, Florence Forziati, and Walter Stone, who obtained the

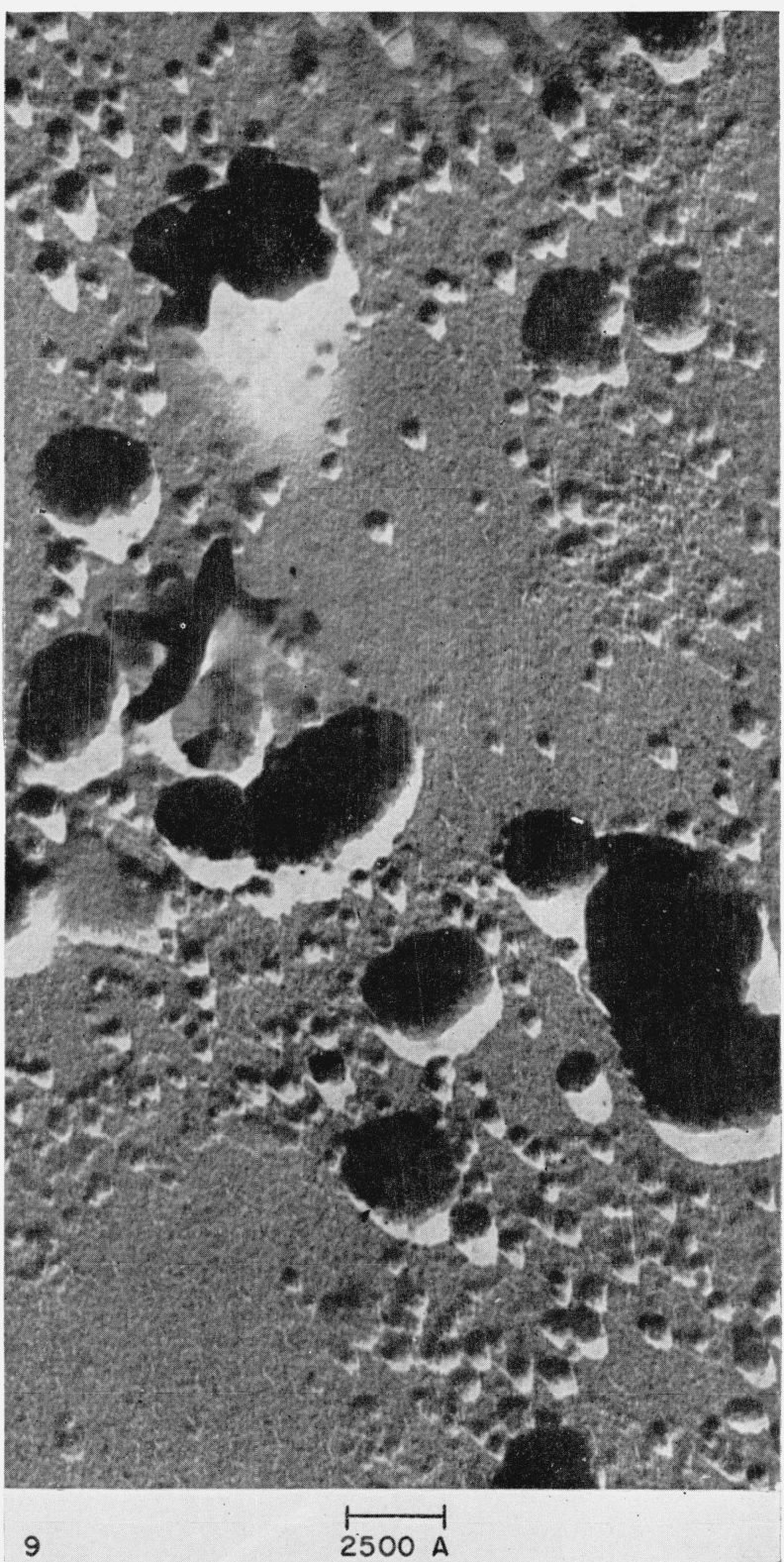

Figure 9. Chromium shadowed electron micrograph of ground powder of blue dyed wool fabric (shadows are white).

infrared absorption spectra. Their assistance is gratefully acknowledged.

Washington, September 1, 1949. 